\title{
Analysing Effects of ISO 9001:2015 Quality Management System on Organizational Communication Structure
}

\author{
Beste Naz Özkan \\ Doctoral School of Sociology and Communication Science, Corvinus University of Budapest, Budapest, Hungary \\ Email: ozkan.naz@stud.uni-corvinus.hu
}

How to cite this paper: Özkan, B. N. (2021). Analysing Effects of ISO 9001:2015 Quality Management System on Organizational Communication Structure. Open Journal of Social Sciences, 9, 85-96.

https://doi.org/10.4236/jss.2021.910006

Received: September 14, 2021

Accepted: October 16, 2021

Published: October 19, 2021

Copyright $\odot 2021$ by author(s) and Scientific Research Publishing Inc. This work is licensed under the Creative Commons Attribution International License (CC BY 4.0).

http://creativecommons.org/licenses/by/4.0/

\begin{abstract}
Today, competitiveness between the companies is challenging. For that reason, the quality and the image of the companies gain importance. It is not sufficient to have good quality products to be able to stay in the game. The process should be able to provide the satisfaction of shareholders. The aim of the essay is to examine ISO 9001:2105 quality management system from the point of organizational communication. With correct organizational communication, companies are able to provide the satisfaction of all shareholders and create an efficient organizational image. Therefore, a system which controls every process and improves the inadequate parts of the company should be implemented. ISO 9001:2015 is one of these systems. The used method in this research is interviewing companies do apply and do not apply ISO 9001:2105 quality management system and makes a comparison between them from the points of internal and organizational communication. According to the results of the current interviews, it can be stated that ISO 9001:2015 does not only help to improve the quality of the product, but it also provides a better understanding of internal and external shareholders and helps them enhance the functioning of the company. Therefore, it can be mentioned that using this mentioned system increases the efficiency and productivity of the company.
\end{abstract}

\section{Keywords}

Organizational Communication, Internal Communication, Quality

Management Systems, ISO 9001:2015

\section{Introduction}

The present essay will be focusing on the evaluation of ISO 9001:2015 quality 
management system criteria from the point of organizational communication. The focus of total quality management is to improve the quality of every process within the organization. In this research, the focus will be organizational communication. As it is stated previously, considerable competition can be observed between companies and every company must prove their quality to survive. This quality concept is not only about the quality of goods or services. If an organization does not give value to its internal and external partners and focuses only on the product, it becomes unsuccessful and cannot stand on through the competition. This time, the success of companies has been evaluated with different variables. Some of them are the value that it gives to their employees, corporate structure, organizational communication, organizational culture, and social responsibilities of business. At this point, ISO 9001:2015 quality management system steps to the scene. Without a system, an organization, however major or minor it shall be, cannot achieve these successes. Organizations must establish a system and have to make a plan for further steps. One of the most crucial aspects of these steps is the controlling level. Because even if an organization follows a system, if there is no controlling part, the system cannot work. The structure of the system must be established based on this concept. The organization should see what the negative and positive sides that it has are, and it must endeavor to improve the negative parts, and try to keep the positive parts at the same level. That is how an organization can reach overall success. This paper interrogates the overall perspective of ISO 9001:2015 quality management system influence on organizational communication. The structure of this paper starts with analyzing organizational communication and total quality management systems deeply. Afterwards the relationship between ISO 9001:2015 total quality management system and organizational communication gets examined. Methodological part and results of the research take the next step of the paper. In the end, conclusion and limitations of the research are shown.

\section{Organizational Communication}

Özgün defines organizational communication as; it is the communication process that takes place within certain rules to ensure coordination, information flow, motivation, integration, evaluation, training, decision making and control among the departments and elements that build the organization, within the production and management process required for the institutions to achieve and operate their goals and objectives (Özgün, 2019). Organizational communication is a way of structuring the flow of information within the organization to define the titles and be aware of the employees' decisions and thoughts. It is an essential part of the organization because without correct organizational communication, a company cannot reach its success and aims. To define internal organizational communication, it can be stated that internal business communication refers to the communication between people who are employed in an organization or between components of an organization or between management and employees. Internal organization communication contains all communicative and 
information activities among the members of an organization (Stevanovic \& Gmitrović, 2015). The author of the present essay suggests that internal communication in a company detects an essential communication network of a company. When the strong network has been built, it ensures the best productivity of the employees. And this productivity also reflects the quality of the product or service. The proper functioning of internal communication relates to the flow of information between employees and managers. As we consider the hierarchical structure in a company, this flow of information becomes more important. When the correct and sufficient information is not given to employees, the quality of the product or service would be decreased. At the same time, the relationship between managers and employees gains much more importance with internal organizational communication. The managers' way of communication affects the motivation of employees. For that reason, communication must constitute the correct and solid direction. Employees must know the definition, the duration of their job and their department. If the company does not give these specifications, the motivation decreases and the work relays. Employees of the company are the internal shareholders. If a definition is given to the concept of shareholder, we can tell the actors who influence the activities of the company and who are influenced. A company has a responsibility towards its shareholders, and it must point them out in new decisions. So, the employees are the internal shareholders of the company. Therefore, the company has a responsibility towards its employees. At this point the internal organizational communication has major importance. In addition to that, organizational communication helps to adopt the organizational culture and organizational identity by internal and external shareholders. The concept of organizational identity was introduced by Albert and Whetten in 1985. Based on their empirical research results, they suggested that organizational identity embodies the characteristics of an organization that its members perceive to be central, distinctive, and enduring (or continuing) in an organization when the past, present and the future is taken into account (Puusa, 2006). Therefore, organizational identity basically refers to the most well-known and used features of the organization. The present thesis supports the view that organizational identity is about a company's internal and external expressions. Organizational identity influences employees and also external shareholders, such as customers. Because if a company has a strong organizational identity and is aware of how to show that, it builds loyalty from the point of the customer. The elements of organizational identity can be defined as the company's building, building's neighborhood, packaging style, and also organization's logo, envelopes, signboard, business cards, brochures, agendas etc. So, all of these elements affect and help to build a strong organizational identity. This essay suggests that in an organization, there should be a correct organizational and internal communication. Otherwise, employees are not able to understand their tasks, that the authorities expect from them and in what structure they should complete the task. This incorrect situation eventually influences the quality of work. In the end, the organization would have unmotivated em- 
ployees, unmotivated managers, unsatisfied customers, and shareholders. For that reason, effective organizational communication is very important in an organization. The author of the present essay states that firstly, the flow of information should be defined in the first place. An employee should know where the task comes from and who the responsible manager is. Internal communication takes place at that point. A company should decide the formal or informal communication in the first place. Because that decision has a big effect on organizational and internal communication and organizational culture. Employees should be aware of their responsibilities and to whom they report. If an organization does not define these points, it can create a huge incomprehensible situation and this situation would affect employees well. The point is that organizational communication reflects the organization's image. It must be given to the employees in the first place and try to make them understand and adopt this concept. The adoption takes time, firstly employees must see the organization's structure, the directors and afterwards they can start to understand that this concept is not only for the company, but also for the employees. Because without effective organizational communication, managers are not able to understand if the employees are satisfied, or not satisfied with the company, with their tasks, and with their colleagues.

\section{Total Quality Management and ISO 9001:2015 Quality Management Standard}

If there is an elaboration about communication in a company, quality has to be considered too, since it influences the information flow, the productivity, the employees and the shareholders. The quality part of the company can be examined by ISO 9001:2015 quality management systems and the connection to these systems from the point of organizational communication. According to the Oxford Dictionary, quality is "The standard of something as measured against other things of a similar kind; the degree of excellence of something". As it has stated, quality is a degree which describes the level of excellence. Total quality management puts the quality into the focus point in an organization. It tries to integrate all the employees to the participation of the organization. Quality management principles determine the attitude of the enterprise and its employees to general problems of the quality. Quality management principles have an effect on quality in a long range and they define the strategy of improvement. Principles are establishing main objectives and tasks of quality policy. By the virtue of the principles, every action in the company is justified and directed. Principles can constitute the set of pointers concerning shaping relationships in the entire enterprise. They can also be directed at employees in specific departments and enterprises in particular (Misztal, 2010). As stated, the principles of quality management systems basically stand for the goals of the systems in an organization. The author of the present essay suggests that total quality management aims for all the employees without leaving anyone and it connects them to the operation of the organization. The goal of total quality management is not 
short term, it aims at long term goals. The management's quality is also very important in total quality management. Because all the managers, supervisors influence the quality of the work. The way they behave, the way they communicate with each other or the employees are essential points of the motivation and quality of business life. For that reason, the way behaviour formulates is very important in an organization. A manager should not be the only one who has power. A manager should have leadership skills, he/she should know how to control behaviours. Total quality management is based on the understanding of the customer needs and expectations. These expectations should be met on time. Therefore, the satisfaction of both internal and external customers should be ensured by the organization. Total quality management treats its employees as internal customers. For the satisfaction of foreign customers, employees should be satisfied first. The satisfaction of external customers is the basis of the organization's existence (Çekiç, 2018). TQM focuses on continuous process improvement within organizations; it is imperative that companies offer superior value to customers, and meet their needs (Nguyen \& Nagase, 2019).

According to ISO 9001, an organization needs to check the actions and improvements that they have done and then check the results. If the organization did not check the results and provided information after the new changes, they could not measure the quality level before and after the application of the quality management system. After checking the process, the organization needs to act on the results. This process cycle was called PDCA (Plan-Do-Check-Act) cycle, as seen in Figure 1. In the "plan" phase, the organization needs to identify the problems. What they need to improve, what they need to change and what the negative parts are which affect the company. The organization needs to improve the positive parts and change the negative parts in the "do" phase. As it is mentioned before, without checking the results, the changes that have been done are not efficient and beneficial for the company. For that reason, the so called "check" phase is very important. It gives the results of the improvement and changes and gives the chance to see before and after phases of the company. The "Act" phase gives the organization the point which is learned through this process.

In other words, the cycle starts with the Plan step. This involves identifying a goal or purpose or a problem, formulating a theory, defining success metrics and putting a plan into action. These activities are included in the Do step, in which the components of the plan are implemented, for example producing a product. Secondly, comes the check (Study) step, the results are being controlled during the process, and the plan's success. Also, it is a step which checks the improvement of the problematic areas. The Act step closes the cycle, integrating the learning generated by the entire process, which can be used to achieve the goal, change methods or even reformulate a theory altogether. These all four steps are repeated over and over as part of a never-ending cycle of continual improvement (Patel \& Desphande, 2017). 


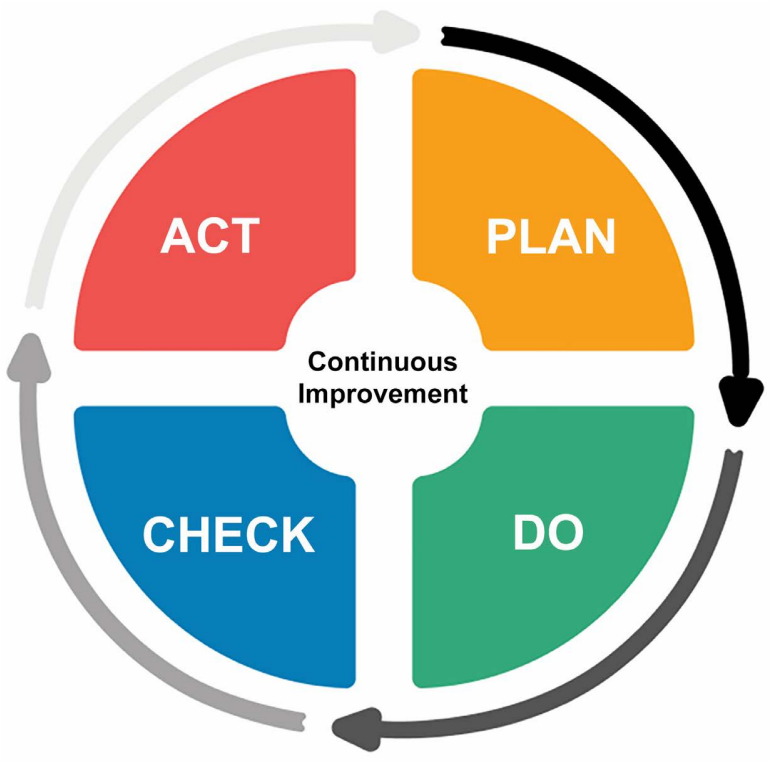

Figure 1. Plan-Do-Check-Act Cycle. (https://kanbanize.com/leanmanagement/improvement/what-is-pdca-cycle/Date of Access: 13.11 .2020$)$.

\section{Examination of ISO 9001:2015 Quality Management Systems and Organizational Communication Relation}

Total quality management aims for the satisfaction of the customers, the employees and other shareholders. Therefore, the employees are one of the most important parts in total quality management. Without the motivation and satisfaction of employees, the job cannot be done perfectly and the quality of work decreases. At one point, the satisfaction of employees depends on the organizational communication because it gets affected by the internal communication and information flow. ISO 9001:2015 is the recent updated version of quality management standard. ISO 9001:2015 provides a continuous improvement to a company with a quality management system. Its goal is to ensure the quality in every process of the organization's structure, from the very beginning to the end. ISO 9001:2015 adopts the process approach and it aims for the satisfaction of all internal and external shareholders. It tries to ensure the quality in every department and every step that the company has. Organisations adopt TQM in hopes of improving efficiency, reliability and quality as well as in support of performance and productivity goals (Dubey, Gunasekaran, Childe, Papadopoulos, Hazen, \& Roubaud, 2018). The aim of ISO 9001:2015 is to improve the quality of the product/service and to minimize the cost of the company. It is not only about the product improvement; it is all about the process improvement. That is how the management systems, the leaders, the satisfaction of employees and customers come into the scene. ISO 9001:2015 aims at the continuous improvement in the organization. To provide that aim, it suggests the quality improvement in the organization from the top management to the customers. ISO 9001:2015 quality management system gives effort to the goal to reach the top 
excellency for the organization. It aims to increase the performance of each department of the organization and at the end to reach the top quality with all the members of the organization. According to ISO 9001, the participation of all the members of the organization in the decision-making steps is very important. Quality management systems do not avoid any of the members. Also, one of the most important parts in ISO 9001 is flow of information. If the flow of information is not correct between the employees and managers, the system cannot work. Therefore, the communication styles should be definite from the very beginning and this communication style should be defined by a correct organizational and internal communication. The efforts of top management in Total Quality Management are essential but not sufficient for success. Management should ensure transparency to help all employees adopt a total quality approach. Ensuring the full participation of employees is very important in terms of using the creativity and priority of the person on certain issues. Employees who have the opportunity to discuss their thoughts and ideas in a healthy communication environment and participate in decisions will be able to add quality to the quality of the work done using their creativity (Bilen \& Sitki, 2020).

\section{Methodology}

The present essay examines the findings of the literature review with the practical part of the research. The methodology of this research was chosen to be qualitative interviews. The author of the present essay has completed six interviews with different companies for data collection. Half of these companies currently have ISO 9001:2015 in their sense, and the other half do not have ISO 9001:2015 system. There will be a comparison between the companies which were interviewed from the point of ISO 9001:2015 and its effects on organizational communication.

\subsection{Sample Details}

First company which has been interviewed is an international company which provides innovative supply chain solutions to its customers. Their main activities are supply chain management and logistic providing. It has around 2000 branches all over the world and they are one of the main land transport providers in Europe, within 430 locations. The second company is a university. It was founded in 1997, in Turkey. It is a foundation university which continues its operation in Istanbul. They have 914 employees in total with academic and administrative personnel. Third company's main business area is AIM and navigation service providing. They have around 50 employees in total in two centers. It has multiple international employees from different nationalities besides Spanish and German, such as Greek, Czech and Estonian. Fourth company is an NGO which is based in the United Kingdom. It works in almost 50 countries to ensure that the voice of minorities is heard. Fifth organization is again an NGO which is a learning experience provider for young people with learning difficulties, sec- 
ondary school students before their career choice, university students trying to find their calling, teachers hungry for innovative pedagogical methods. The last organization was founded in Hungary in 2012. It is a wholesaler of fresh fruit and vegetables in the Hungarian wholesale market in Budapest.

\subsection{Interview Questions}

There are 18 interview questions for the companies which have the ISO 9001:2015 system. First three questions were about the features of the companies, for example "When was the company founded?" and "How many employees do you have?”. After the questions about ISO 9001:2015 system and organizational communication comes into the scene. The purpose of these questions is to understand how ISO 9001:2015 quality management system influences the structure of the companies from the point of organizational communication. 15 questions of the interviews are supposed to examine and evaluate the effect of quality management systems on organizational communication which mostly includes corporate culture and internal communication structure of the organization. For instance, "What are the benefits of using ISO 9001: 2015 quality management system for your business?" or "Do you consider ISO 9001: 2015 quality management system as a help for correct organizational communication?". These questions help to understand which kind of differences a company had after the implementation of ISO 9001:2015 quality management system and how these changes influenced the organizational communication actions and structure in the company. There are 12 interview questions for the companies which do not have the ISO 9001:2015 system. The first three questions are the same with the other group to understand the features of the companies. The other questions are about to see why these companies did not choose to implement the ISO 9001:2015 quality management system and how they think about the system. For example, the question of "Do you think it would be beneficial if you would have ISO 9001: 2015 quality management system as a help for correct organizational communication?" is asked to understand the perception of the companies about the ISO 9001:2015 system and how they think about the beneficial parts of the system on the organizational communication structure.

\section{Results}

According to the interviews that have been conducted, the author of the present essay states that the ISO 9001:2015 quality management system usually works efficiently within companies. It helps employees of the organization to be more motivated and it increases the working performance because it avoids the confusions in the organization such as job descriptions, documentation problems, communication issues. For the organizations, it is a very important point to understand that ISO 9001:2015 is not a product development system, it is a process improvement approach, and it always suggests the continuous improvement and 
quality in the organization. Thus, the companies which implemented the system believe that it is very efficient also from the point of internal and organizational communication. Firstly, it affects the organizational image and reputation of the company in the market. Secondly, by the virtue of supporting the communication flow and defining the communication styles in the organization, employees do know what they would do and to whom they would report, so there would not be a difficulty between the staff and the managers. Also, ISO 9001:2015 supports the adoption of organizational culture from the side of all employees, because it states that without the participation of the staff, processes would not work efficiently, so companies can only ensure the participation of the employees with common belief and values. For that reason, organizational culture has an important role during the implementation of ISO 9001:2015 quality management system. All companies have different values, so it is necessary to define them from the very beginning and be specific about them. As it is mentioned before, organizational communication and internal communication come into the scene at this point. The activities of organizational communication should be defined efficiently for the personals because without an effective communication flow in the organization, employees cannot be motivated, and it affects their performance, so it affects the quality of the work. Organizational communication is a communication process within the departments of the company to assure the aims and goals of the organization. This process contains trainings, organizations, communication flow, control and so on. At this point, ISO 9001:2015 provides the organizations with a correct system to build a successful organizational communication which affects the goals of the company. As it can see from the below table, regarding the opinions from the interviewed companies which do not have the system, it can be said that small size organizations usually do not tend to implement this system because it is easier for them to build a correct system in a small organization. Or sometimes companies believe the system is not relevant to their way of working. Even though ISO 9001:2015 has been developed for every type of company, the main problem is that some of the companies think that this system is only for the quality of the service or product (Table 1 ).

At the end of the interviews, it is seen that ISO 9001:2015 quality management system is efficient for the organizations from the point of organizational communication. And it gives the impression to the companies that without motivated employees, the required quality of work cannot be achieved. To assure motivation, the requirements of ISO 9001:2015 are very essential, for instance the participation of the employees to every process of the business. On the other hand, ISO 9001:2015 improves the documentation and standardization system and it avoids the conflicts and confusions between the employees and managers. Organizational communication is a crucial part in this system and according to the interviews which were held for this research, the system assures the required qualifications for organizational communication. 
Table 1. Company details.

\begin{tabular}{|c|c|c|c|c|c|c|}
\hline & University of $M$ & DB Schenker & Group EAD & NGO D & Minority Rights & Company $\mathrm{K}$ \\
\hline $\begin{array}{l}\text { Does company } \\
\text { have the ISO } 9001 \\
\text { QMS system? }\end{array}$ & $\begin{array}{l}\text { Has the certification } \\
\text { of ISO } 9001: 2015 \text { since } \\
2018\end{array}$ & $\begin{array}{l}\text { Has the certification } \\
\text { for almost } 20 \text { years }\end{array}$ & $\begin{array}{l}\text { Has the certification } \\
\text { since } 2019\end{array}$ & No & No & No \\
\hline $\begin{array}{l}\text { Does company } \\
\text { have international } \\
\text { employees? }\end{array}$ & $\begin{array}{l}\text { Has international } \\
\text { employees and students }\end{array}$ & $\begin{array}{l}\text { Has international } \\
\text { employees }\end{array}$ & $\begin{array}{l}\text { Has international } \\
\text { employees }\end{array}$ & No & Yes & Yes \\
\hline $\begin{array}{l}\text { What are the main } \\
\text { reasons to use the } \\
\text { system/to not use } \\
\text { the system? }\end{array}$ & $\begin{array}{l}\text { Documentation } \\
\text { systems, risk } \\
\text { management, process } \\
\text { approach, positive } \\
\text { improvements for } \\
\text { internal/external } \\
\text { shareholders, } \\
\text { Plan-Do-Check-Act } \\
\text { Cycle }\end{array}$ & $\begin{array}{l}\text { To communicate } \\
\text { efficiently with local } \\
\text { and international } \\
\text { employees, to build a } \\
\text { coherence, to get help } \\
\text { from management, } \\
\text { a successful } \\
\text { organizational culture, } \\
\text { employees' motivation }\end{array}$ & $\begin{array}{l}\text { Efficiency in providing } \\
\text { the services, high quality } \\
\text { service and product, } \\
\text { improvement of internal } \\
\text { and external } \\
\text { communication, } \\
\text { standardization, basically } \\
\text { continuous improvement } \\
\text { in every department of } \\
\text { the organization }\end{array}$ & $\begin{array}{l}\text { Small size of } \\
\text { employees (8) }\end{array}$ & $\begin{array}{l}\text { QMS is too } \\
\text { complex to set } \\
\text { up and not really } \\
\text { relevant to their } \\
\text { business area }\end{array}$ & $\begin{array}{l}\text { Thinks it would } \\
\text { be beneficial for } \\
\text { them, but they did } \\
\text { not have time and } \\
\text { human source to } \\
\text { implement the } \\
\text { system }\end{array}$ \\
\hline $\begin{array}{l}\text { Does company } \\
\text { recommend the } \\
\text { system/consider } \\
\text { having the system } \\
\text { in the future? }\end{array}$ & $\begin{array}{l}\text { Yes, company } \\
\text { recommends the } \\
\text { system }\end{array}$ & $\begin{array}{l}\text { Yes, company } \\
\text { recommends the } \\
\text { system }\end{array}$ & $\begin{array}{l}\text { Yes, company } \\
\text { recommends the system }\end{array}$ & $\begin{array}{l}\text { Yes, company } \\
\text { considers } \\
\text { having the } \\
\text { system }\end{array}$ & No & $\begin{array}{l}\text { Yes, company } \\
\text { considers having } \\
\text { the system }\end{array}$ \\
\hline
\end{tabular}

\section{Conclusion and Limitations}

The present essay focused on how ISO 9001:2015 quality management system influences the organizational structure of a company and how it affects the employees' motivation and performance regarding taking into consideration organizational communication, internal communication, and organizational culture. The aim of the research was to evaluate ISO 9001:2015 principles and criteria from the point of organizational communication and to examine its effects on internal and external shareholders, especially on the employees. For that reason, the methodology of the research is determined as an interview to understand the companies which have, and which do not have the system in their sense. The author of the present essay aimed to understand the beneficial parts of the ISO 9001:2015 system on the companies while interviewing both sides. The generated results from the research and interviews are significant to see that ISO 9001:2015 influences organizational communication and organizational culture in the company and it supports having an efficient organizational structure and relationship with all the shareholders to ensure the quality and continuous improvement in the company. Regarding the essential points of the system, it states that there should be an effective relationship with all of the shareholders of the company but especially with the employees. Focusing on employees and the communication with the employees is one of the important parts in ISO 9001:2015 system. ISO 9001:2015 is a process approach so it is essential to build a structure in the company and follow it. The system always mentions that the parts should be improved in the company, and there is a PDCA cycle to see the 
results of the improvement and control the situation. As it is previously mentioned, ISO 9001:2015 quality management system tries to create a continuous improvement and assurance of the quality for all departments of the company. The author of the present essay states that ISO 9001:2015 has a big impact on organizational communication and organizational culture. Because regarding its sense and its requirements, communication is one of the essential points in the company. To improve the internal communication and provide a correct communication flow between the employees and management, it is necessary to have a structure. Based on the results and interpretations of this research, the author states that this essay is significant from the points of understanding ISO 9001:2015 quality management system toward organizational communication and organizational culture. As mentioned above, communication strategies of a company play a crucial role in ensuring productivity and motivation of the team members. This research practically analyzed that ISO 9001:2015 system contributes to the structure of the company and supports to increase the motivation and quality of work of the employees. For that reason, the contribution of this research could be defined as investigating the practical effects of ISO 9001:2015 quality management system on improving organizational communication strategies in the companies and according to this improvement, increasing the productivity of the employees.

Although the author of the present research made interviews with multiple companies which are in different size and different business fields, this research cannot be generalized for all the business enterprises in the world. For further research in this area, the companies which do not have ISO 9001:2015 quality management system can be analyzed from employees' point of views with a survey to be able to understand if they are comfortable and motivated with the established system. Because even though this research investigated the effects of ISO 9001:2015 on organizational communication strategies in the companies, it is still questionable that how employees adopt this system.

\section{Conflicts of Interest}

The author declares no conflicts of interest regarding the publication of this paper.

\section{References}

Bilen, A., \& Sitki, A. (2020). The Impact of Total Quality Management on Patient Satisfaction: A Field Study in the Health Centers of the Syrians in Gaziantep. Journal of Arts \& Social Sciences, 7, 11-20. https://doi.org/10.46662/jass-vol7-iss1-2020(11-20)

Çekiç, A. (2018). ISO 9001:2015 Kalite Yönetim Sisteminin Getirdiği Yenilikler İle EFQM Mükemmellik Modelinin Karşılaştırılması ve İlişkiler Açısından Bir Araştırma (Comparison of EFQM Excellence Model with Innovations Brought by ISO 9001: 2015 Quality Management System). Master Thesis, Istanbul Okan University.

Dubey, R., Gunasekaran, A., Childe, S. J., Papadopoulos, T., Hazen, B. T., \& Roubaud, D. (2018). Examining Top Management Commitment to TQM Diffusion Using Institu- 
tional and Upper Echelon Theories. International Journal of Production Research, 56, 2988-3006. https://doi.org/10.1080/00207543.2017.1394590

Misztal, A. (2010). Eight Quality Management Principles-Practical Context. In A. Borucki, \& L. Pacholski (Eds.), Some Problems and Methods of Ergonomics and Quality Management (pp. 125-136, Chapter X). Publishing House of Poznan University of Technology.

Nguyen, T. L. H., \& Nagase, K. (2019). The Influence of Total Quality Management on Customer Satisfaction. International Journal of Healthcare Management, 12, 277-285. https://doi.org/10.1080/20479700.2019.1647378

Özgün, D. (2019). Ofis Dizaynının Kurumsal İletişim Açısından İncelenmesi (Investigation of Office Design from Corporate Communication). Master Thesis, Marmara University.

Patel, P., \& Deshpand, V. (2017). Application of Plan-Do-Check-Act Cycle for Quality and Productivity Improvement-A Review. International Journal for Research in Applied Science \& Engineering Technology, 5, 197-201.

Puusa, A. (2006). Conducting Research on Organizational Identity. Electronic Journal of Business Ethics and Organization Studies, 11, 24-28.

Stevanovic, M., \& Gmitrović, A. (2015). Importance and Role of Internal Communication in Organizations. Applied Mechanics and Materials, 806, 302-307.

https://doi.org/10.4028/www.scientific.net/AMM.806.302 